Quim. Nova, Vol. 34, No. 1, 16-20, 2011

\title{
RESPOSTA ANTIOXIDANTE, FORMAÇÃO DE FITOQUELATINAS E COMPOSIÇÃo DE PIGMENTOS FOTOPROTETORES EM Brachiaria decumbens Stapf SUBMETIDA À CONTAMINAÇÃO COM Cd E Zn
}

\author{
Fabiana Soares dos Santos \\ Departamento de Engenharia de Agronegócios, Universidade Federal Fluminense, Av. dos Trabalhadores, 420, 27255-125 \\ Volta Redonda - RJ, Brasil \\ Nelson Moura Brasil do Amaral Sobrinho e Nelson Mazur* \\ Departamento de Solos, Instituto de Agronomia, Universidade Federal Rural do Rio de Janeiro, BR 465, km 7, 23890-000 \\ Seropédica - RJ, Brasil \\ Carlos Garbisu \\ Departamento de Ecosistemas, Instituto Vasco de Investigación y Desarrollo Agrario, Berreaga 1, E-48160 Derio, Bizkaia, Espanha \\ Oihana Barrutia y José Maria Becerril \\ Departamento de Biología Vegetal Y Ecología, Universidad del País Vasco, PO Box 644, E-48080 Bilbao, Espanha
}

Recebido em 4/11/09; aceito em 13/7/10; publicado na web em 16/11/10

\begin{abstract}
ANTIOXIDATIVE RESPONSE, PHYTOCHELATIN PRODUCTION AND PHOTOPROTECTIVE PIGMENTS COMPOSITION OF Brachiaria decumbens Stapf PLANTS EXPOSED TO Cd AND Zn. In order to evaluate the response of Brachiaria decumbens Stapf to $\mathrm{Cd}$ and $\mathrm{Zn}$, plants were hydroponically exposed to 50 and $100 \mu \mathrm{mol} \mathrm{L}-1$ of $\mathrm{Cd}$ and 500 and $2000 \mu \mathrm{mol} \mathrm{L}^{-1}$ of $\mathrm{Zn}$. Metal content of shoots and roots was determined, as well as alterations in photosynthetic and photoprotective pigments, antioxidant metabolites and phytochelatin synthesis. Plants concentrated elevated levels of $\mathrm{Cd}$ and $\mathrm{Zn}$, especially in roots. Zinc exposure negatively affected chlorophyll and $\beta$-carotene content, whereas the highest dose of $\mathrm{Cd}$ reduced VAZ cycle pigments and tocopherol levels in plant shoots. Cadmium was the maximum inducer of the phytochelatin synthesis pathway.
\end{abstract}

Keywords: phytoremediation; phytochelatin; tocopherol.

\section{INTRODUÇÃO}

As plantas diferem na sua habilidade em retirar, acumular e tolerar metais pesados, podendo ocorrer diferenças marcantes entre as espécies, entre variedades de uma mesma espécie e, também, nos tecidos da planta. ${ }^{1}$ As plantas tolerantes a metais pesados têm mecanismos eficientes para restringir o excesso de metais pesados livres nos compartimentos celulares, ${ }^{2}$ incluindo a exclusão, formação de peptídeos ricos em grupos tiólicos (fitoquelatinas e metalotioneínas), quelação por ácidos orgânicos e aminoácidos, compartimentalização de metal em estruturas subcelulares, ${ }^{3}$ além de mecanismos enzimáticos e não enzimáticos de proteção contra o estresse oxidativo. ${ }^{4}$ Alguns dos mais importantes antioxidantes são a glutationa reduzida (GSH), ascorbato (vitamina C), alfa-tocoferol (vitamina E) e os carotenoides, que são encontrados nas plantas em altas concentrações. ${ }^{5}$

O aparato fotossintético é extremamente sensível a metais pesados. ${ }^{2,6}$ Os pigmentos primários são os que têm como principal finalidade a captação de energia luminosa, como a clorofila $a$, sendo também acompanhados de outros pigmentos acessórios como os carotenoides, que incluem os carotenos e as xantofilas, cuja função é, por um lado, ampliar o espectro de absorção dos pigmentos primários e, por outro, servir de proteção na dissipação de energia excedente. ${ }^{5}$

Brachiaria decumbens Stapf é uma espécie de planta nativa da África e amplamente cultivada nos trópicos. É caracterizada pela sua alta produção de biomassa, uso intensivo e elevada resistência a altas concentrações de alumínio no solo. ${ }^{7}$ Esta espécie apresenta potencial para se desenvolver em solos contaminados com $\mathrm{Cd}, \mathrm{Zn}$ e $\mathrm{Pb} .{ }^{8}$

Este trabalho teve como objetivo determinar a indução da resposta antioxidante, conteúdo de clorofila e de pigmentos fotoprotetores

*e-mail: nelmazur@ufrrj.br em amostras de $B$. decumbens cultivadas e que foram submetidas a diferentes concentrações de $\mathrm{Cd}$ e $\mathrm{Zn}$.

\section{PARTE EXPERIMENTAL}

Sementes de $B$. decumbens foram colocadas para germinar em mistura de perlita e vermiculita. Sessenta dias após a germinação, as plantas foram transferidas para vasos contendo solução nutritiva de Hoagland ${ }^{9}$ a metade da força iônica e modificada, conforme composição (em $\mu$ mol L-1 $)^{-1} \mathrm{KNO}_{3}, 5044 ; \mathrm{Ca}\left(\mathrm{NO}_{3}\right)_{2}$ x $4 \mathrm{H}_{2} \mathrm{O}, 1490$; $\mathrm{NH}_{4} \mathrm{H}_{2} \mathrm{PO}_{4}, 10 ; \mathrm{MgSO}_{4}$ x $7 \mathrm{H}_{2} \mathrm{O}, 98,8 ; \mathrm{H}_{3} \mathrm{BO}_{3}, 23,12 ; \mathrm{MnCl}_{2}$ x $4 \mathrm{H}_{2} \mathrm{O}$, 4,$58 ; \mathrm{CuSO}_{4} \times 5 \mathrm{H}_{2} \mathrm{O}, 0,16 ; \mathrm{ZnSO}_{4} \times 7 \mathrm{H}_{2} \mathrm{O}, 0,04 ; \mathrm{Na}_{2} \mathrm{MoO}_{4}$ x $2 \mathrm{H}_{2} \mathrm{O}$, 0,22; FeEDDHA, 10. Cinco dias após o transplante, a solução nutritiva foi enriquecida com 50 e $100 \mu \mathrm{mol} \mathrm{L}^{-1}$ de Cd e 500 e $2000 \mu \mathrm{mol} \mathrm{L}^{-1}$ de $\mathrm{Zn}$, na forma de nitrato. As diferenças do conteúdo de nitrato entre os tratamentos foram compensadas pela adição de $\mathrm{KNO}_{3}$. O pH da solução nutritiva foi mantido em 5,5.

Raízes e folhas dessas plantas foram coletadas antes da contaminação e após 1, 3 e 6 dias da aplicação dos metais. Após a colheita, raízes e folhas foram pesadas e separadas. As raízes foram colocadas em solução aquosa de $\mathrm{CaCl}_{2} 10 \mathrm{mmol} \mathrm{L}^{-1}$ por 10 min e posteriormente lavadas com água desionizada. Parte do material foi separado para determinação de metais e o restante foi congelado em nitrogênio líquido, sendo posteriormente armazenados $\mathrm{a}-80^{\circ} \mathrm{C}$ em ultrafreezer, até serem liofilizados.

O material separado para determinação de metais foi levado à estufa a $70{ }^{\circ} \mathrm{C}$ até peso constante e foi feita digestão nitro-perclórica $6: 1 .{ }^{10} \mathrm{As}$ concentrações de $\mathrm{Cd}$ e $\mathrm{Zn}$ foram medidas em espectrômetro de absorção atômica, empregando-se chama de ar-acetileno e equipamento modelo Varian SpectrAA-250 Plus. As análises foram realizadas com limite de detecção de 0,0022 e 0,0012 $\mathrm{mg} \mathrm{L}^{-1}$ para Cd e Zn, respectivamente; 
limite de quantificação de 0,025 para Cd e Zn; e comprimento de onda de 228,8 e 213,9 nm para Cd e Zn, respectivamente.

A extração e estimativa do conteúdo dos compostos tiólicos foi realizada de acordo com Hernández-Allica et al.. ${ }^{11}$ Fitoquelatinas (PC) e tioles de baixa massa molar, como glutationa reduzida (GSH), foram analisados por cromatografia em fase líquida de alta eficiência (CLAE), usando um equipamento Waters (Milford, MA, USA) equipado com um autoinjetor 717 Plus, detector de fotodiodos PDA 996 e detector de fluorescência SFD 474. Todo o sistema cromatográfico foi controlado pelo software Milenium, com longitude de onda de excitação de $365 \mathrm{~nm}$ e de emissão de $470 \mathrm{~nm}$. A cromatografia foi realizada em uma coluna Nova-Pak C18 (3,9 mm x $150 \mathrm{~mm}, 4 \mu \mathrm{m})$.

A fase móvel foi composta por solvente A, metanol (100\%) e solvente B, água:metanol:ácido acético $(89,75: 10: 0,25)$. PC e GSH foram separadas a uma temperatura de $25{ }^{\circ} \mathrm{C}$ em $36 \mathrm{~min}$, usando-se o seguinte gradiente de eluição da fase móvel: 0-15 min, 0-4,5\% de solvente A; $15-22 \mathrm{~min}, 4,5-40 \%$ de solvente A; 22-26 min, 40-100\% de solvente A; 26-32 min, 100-0\% de solvente A; 32-36 min, $100 \%$ de solvente B. O fluxo dos solventes foi de $1,5 \mathrm{~mL} \mathrm{~min}^{-1}$.

O conteúdo total de fitoquelatinas foi estimado como um total dos sinais individuais de cada fitoquelatina e expresso em nmolGSH g ${ }^{-1} \mathrm{PS}$ (peso seco), baseado na área do padrão de glutationa reduzida. ${ }^{11}$

Para análise de ascorbato reduzido (AsA) e de-hidroascorbato (DHA), 0,15 g de amostra de raízes e folhas foram extraídas com nitrogênio líquido em almofariz de ágata previamente resfriado. Posteriormente, foi homogeneizado em $2,25 \mathrm{~mL}$ de uma solução contendo $3 \%$ de $\mathrm{HCl}$ e EDTA $1 \mathrm{mmol} \mathrm{L}^{-1}$. O extrato foi centrifugado a $15000 \mathrm{~g}$ durante $5 \mathrm{~min}$ e $200 \mu \mathrm{L}$ do sobrenadante foram neutralizados com $600 \mu \mathrm{L}$ de água ultrapura e $200 \mu \mathrm{L}$ de tampão succinato (succinato $\left.1 \mathrm{~mol} \mathrm{~L}^{-1}+\mathrm{KOH} 0,5 \mathrm{~mol} \mathrm{~L}^{-1}\right) .{ }^{12} \mathrm{~A}$ forma reduzida do ascorbato foi medida em espectrofotômetro por um decréscimo na absorvância a $265 \mathrm{~nm}$ após adição de 10 unidades $\mathrm{mL}^{-1}$ de ascorbato oxidase, e a forma oxidada (de-hidroascorbato) pelo aumento na absorvância em $265 \mathrm{~nm}$ após redução com $20 \mu \mathrm{L}$ de ditiotreitol $100 \mathrm{mmol} \mathrm{L}^{-1}$.

Para análise de pigmentos fotossintéticos e tocoferol foram coletadas amostras de folha em discos de $5 \mathrm{~mm}$ de diâmetro, antes de amanhecer o dia, sendo congeladas em nitrogênio líquido e armazenadas em ultrafreezer a $-80{ }^{\circ} \mathrm{C}$ para análise. A extração foi realizada utilizando-se um homogeneizador elétrico modelo Tissue Tearor 985370 a $5000 \mathrm{rpm}$ com $1 \mathrm{~mL}$ de acetona a $100 \%$. Os extratos foram centrifugados a $13200 \mathrm{rpm}$ a $4{ }^{\circ} \mathrm{C}$ durante $20 \mathrm{~min}$ e o sobrenadante foi recolhido e passado por filtro de $0,22 \mu \mathrm{m}$ de malha para análise. A quantificação de pigmentos fotossintéticos e tocoferol foi feita por CLAE, controlada pelo programa Empower Pro (Waters Corporation, USA). A cromatografía foi feita em uma coluna de fase reversa Spherisorb ODS-1 (5 $\mu \mathrm{m}, 4,6 \mathrm{~mm}$ x $250 \mathrm{~mm}$; Waters, Irlanda) precedida de uma pré-coluna Nova-Pak C-18 (4 $\mu \mathrm{m}, 3,9$ mm x 20 mm; Waters, Irlanda). ${ }^{13,14}$ A pressão do sistema foi de aproximadamente 800 psi e o volume de injeção foi de $15 \mu \mathrm{L}$. A fase móvel foi composta de dois solventes, sendo o solvente A: acetato de etila:metanol:tampão Tris- $\mathrm{HCl}\left(0,1 \mathrm{~mol} \mathrm{~L}^{-1} ; \mathrm{pH} 8\right)(84: 2: 14)$ e o solvente B: metanol:acetato de etila (68:32). Os pigmentos e tocoferol foram separados em $16 \mathrm{~min}$, usando-se um gradiente linear de $100 \%$ de solvente A até $100 \%$ de solvente B nos 10 primeiros min, seguidos de uma eluição de $100 \%$ de solvente B por 6 min. Em seguida, se estabeleceu um gradiente linear de $1 \mathrm{~min}$ de $100 \%$ de solvente B a $100 \%$ de solvente A, e se manteve uma eluição de $100 \%$ de solvente A durante os próximos 8 min para reequilibrar a coluna até a análise da amostra seguinte. $\mathrm{O}$ fluxo dos solventes foi de $1,2 \mathrm{~mL} \mathrm{~min}^{-1}$.

\section{RESULTADOS E DISCUSSÃO}

O aumento na concentração de metais pesados nas plantas foi cor- relacionado com a dose e o tempo de exposição aos metais estudados (Figura 1). As plantas apresentaram maiores concentrações de Zn e Cd após 6 dias de exposição a $100 \mu \mathrm{mol} \mathrm{L}^{-1}$ de Cd e $2000 \mu \mathrm{mol} \mathrm{L}^{-1} \mathrm{de} \mathrm{Zn}$.
(A)

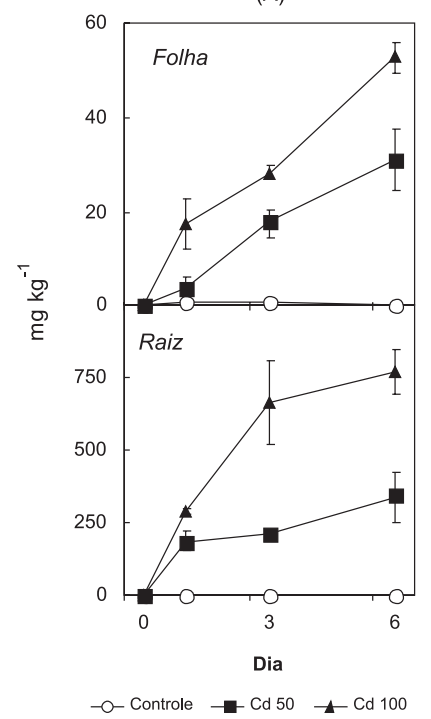

(B)

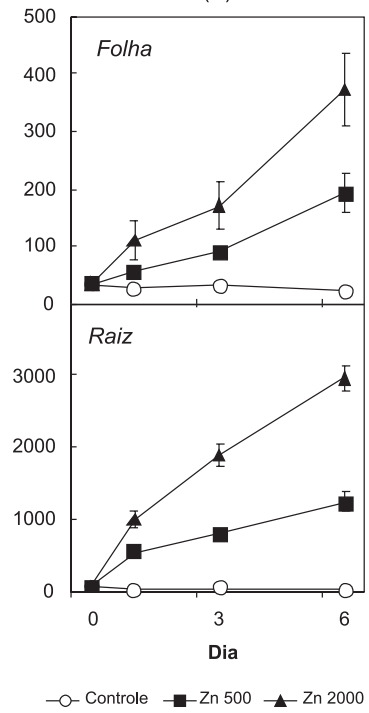

Figura 1. Concentrações de $C d(A)$ e $Z n$ (B) nas plantas de B. decumbens submetidas a diferentes doses de $\mathrm{Zn}$ e $\mathrm{Cd}$ em solução nutritiva. As doses dos diferentes tratamentos de metais estão expressas em $\mu \mathrm{mol} L^{-1}$. Cada valor corresponde a uma média de 3 repetições \pm erro padrão

As raízes foram o principal local de acúmulo de metais pesados nas plantas, a partir do primeiro dia de exposição ao metal. Com relação ao $\mathrm{Cd}$, os resultados mostraram que as raízes acumularam aproximadamente 10 vezes mais metal que a parte aérea nas doses estudadas, enquanto que para o $\mathrm{Zn}$, aproximadamente 5 vezes mais. Devido à principal entrada de metais pesados ocorrer pelas raízes, as plantas tendem a concentrar as maiores concentrações de metais pesados nesse órgão. ${ }^{15}$

Os níveis de GSH reduziram a partir do primeiro dia de exposição ao metal, tanto na parte aérea (Figura 1S, material suplementar) como nas raízes (Figura 2), com exceção do tratamento $\mathrm{Zn} 500 \mu \mathrm{mol} \mathrm{L}{ }^{-1}$, no qual houve uma indução nesses níveis, nas folhas, nas primeiras 24 h de exposição ao metal, reduzindo os níveis após esse período (Figura 1S, material suplementar). Esse decréscimo provavelmente ocorreu devido ao uso desses compostos na formação de fitoquelatinas. A geração de estresse oxidativo por metais pesados pode ser explicada pela redução na capacidade antioxidante da planta, em virtude da redução nos níveis de GSH para a biossíntese de fitoquelatinas. ${ }^{16-18}$ A redução nos níveis de GSH pode ser também explicada pela sua ação quelante com metais pesados. ${ }^{19}$

A redução de GSH ocorreu de maneira mais acentuada na parte aérea das plantas, principalmente no $6^{\circ}$ dia de exposição aos metais estudados (Figura 1S, material suplementar). Considerando que esses compostos podem ser translocados pelos vasos condutores, pode-se considerar que parte desses antioxidantes formados nas folhas pode ter sido translocado para as raízes para a formação de fitoquelatinas, devido aos maiores teores de metais pesados nessa parte da planta (Figura 1).

A síntese de fitoquelatinas foi influenciada pelo tipo e tempo de exposição ao metal (Figura 2). A maior resposta à contaminação relacionada à síntese de fitoquelatinas foi com o $\mathrm{Cd}$, sendo que as plantas desses tratamentos formaram uma maior quantidade de fitoquelatinas em relação aos metais, principalmente na raiz. Cádmio é considerado o mais forte indutor na síntese de fitoquelatinas em muitas plantas ${ }^{20}$ e o mais efetivo ativador da fitoquelatina sintase. ${ }^{21}$ 

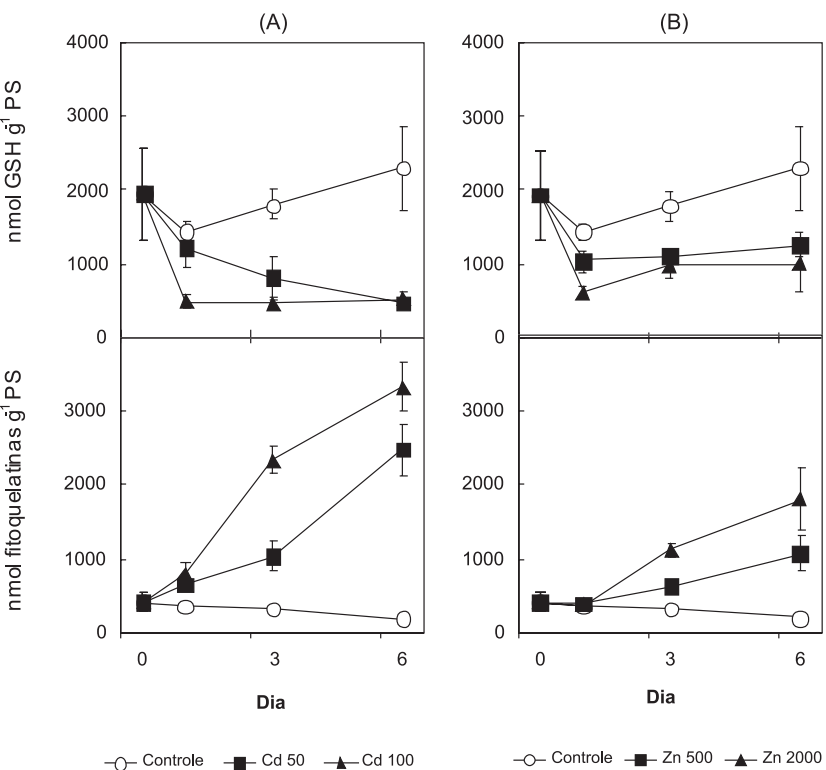

Figura 2. Teores de glutationa reduzida $(G S H)$ e fitoquelatinas nas raízes das plantas de $B$. decumbens submetidas a diferentes tratamentos com $\mathrm{Cd}(\mathrm{A})$ $e \mathrm{Zn}(B)$. As doses dos diferentes tratamentos de metais estão expressas em $\mu \mathrm{mol} \mathrm{L}^{-1}$. Cada valor corresponde a uma média de 3 repetições \pm erro padrão

A produção de fitoquelatinas respondeu à concentração de metal presente na solução nutritiva. As maiores doses de $\mathrm{Cd}$ e $\mathrm{Zn}$ aplicadas, 100 e $2000 \mu \mathrm{mol} \mathrm{L}^{-1}$, respectivamente, acumularam uma maior quantidade de fitoquelatinas nas raízes quando comparadas às menores doses, 50 e $500 \mu \mathrm{mol} \mathrm{L}^{-1}$.

Nas folhas das plantas de braquiária, fitoquelatinas foram induzidas pela exposição aos metais em uma quantidade muito menor que nas raízes, devido provavelmente à maior quantidade de metal acumulado nas raízes. As fitoquelatinas são peptídeos sintetizados enzimaticamente, sendo essa enzima estimulada pela concentração de metal livre presente na célula. ${ }^{22}$

Foi observada produção de fitoquelatinas a partir do $1^{\circ}$ dia para todos os metais nas raízes, no entanto, a maior produção ocorreu no $6^{\circ}$ dia de exposição aos metais. A alta persistência de fitoquelatinas sugere que esses compostos podem ter um papel importante no processo de desintoxicação de íons metálicos nessas plantas. No entanto, os altos níveis de metal acumulados na raiz em relação à capacidade quelante das fitoquelatinas produzidas indicam que esses compostos não seriam suficientes para justificar a quelação de metal nesse órgão.

Em estudos de produção de fitoquelatinas pela hiperacumuladora Thlaspi caerulescens em solução nutritiva contaminada com diferentes doses de $\mathrm{Cd}$, foram encontrados níveis de fitoquelatinas semelhantes aos encontrados em $B$. decumbens. Isso demonstra que o papel das fitoquelatinas pode estar mais relacionado com a tolerância ou homeostase a metais do que com a capacidade hiperacumuladora. ${ }^{11}$

Tanto na raiz como na parte aérea das plantas foram encontradas elevadas quantidades de um composto não identificado, com tempo de retenção próximo ao da glutationa. Existem claros resultados que plantas da família Poaceae apresentam, além da glutationa, uma substância homóloga chamada hidroximetil-glutationa (hm-GSH), presente em algumas plantas da família Poaceae, como o arroz. ${ }^{23}$ Esses dados sugerem que a $B$. decumbens também pode apresentar esse composto, por ser uma planta da família Poaceae.

Com relação aos níveis de ascorbato (Figura 3), observa-se que $\mathrm{Cd}$ e $\mathrm{Zn}$ induziram a resposta antioxidante pelo aumento de AsA na raiz até o $3^{\circ}$ dia de tratamento com os metais, reduzindo os níveis a partir desse dia, provavelmente, devido à redução nos níveis de GSH.
O GSH é o responsável pela reciclagem de ascorbato da forma oxidada para a reduzida pela enzima de-hidroascorbato redutase. ${ }^{24}$ Assim, os teores de ascorbato oxidado (DHA) foram maiores nos tratamentos com metais quando comparados ao controle, provavelmente, devido ao uso do AsA nos processos antioxidantes, transformando o AsA em monode-hidroascorbato, que irá dismutar para de-hidroascorbato (DHA) e ascorbato. A geração do estresse oxidativo por metais pesados pode explicar a redução da capacidade antioxidante da planta, devido à redução nos níveis de glutationa para a síntese de fitoquelatinas. ${ }^{25}$

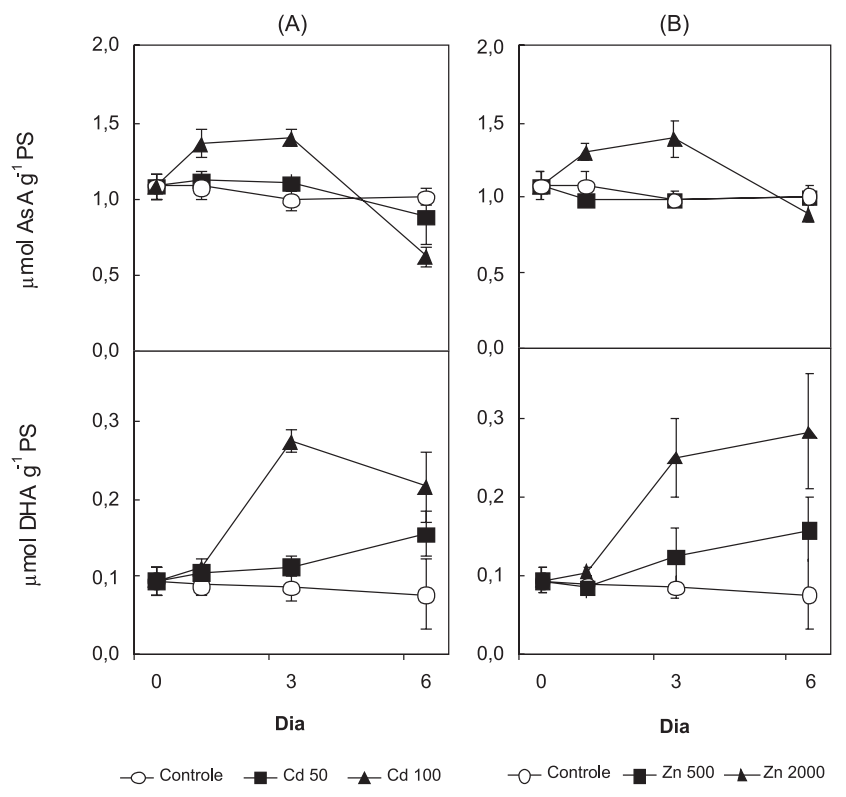

Figura 3. Teores de ascorbato reduzido (AsA) e de-hidroascorbato (DHA) nas raízes das plantas de $B$. decumbens submetidas a diferentes doses de $C d(A)$ e Zn (B). As doses dos diferentes tratamentos de metais estão expressas em $\mu \mathrm{mol} \mathrm{L}^{-1}$. Cada valor corresponde a uma média de 3 repetições \pm erro padrão

No entanto, a depleção de AsA, a partir do $3^{\circ}$ dia de exposição ao $\mathrm{Zn}$ e $\mathrm{Cd}$, não foi proporcional ao aumento nos níveis de DHA (Figura 3). A depleção de AsA sem mudança no estado redox pelo excesso de metais pesados também já foi observada em plantas de feijão ${ }^{26}$ e cevada. ${ }^{27}$

Tem sido reportado que o ascorbato é a principal fonte de ácido oxálico em muitas espécies ${ }^{28}$ e a imobilização do excesso de metais pesados por oxalato tem sido sugerida como um mecanismo de desintoxicação a metais pesados. ${ }^{29}$ Dessa forma, uma possível explicação para a redução nos níveis de ascorbato poderia ser um aumento na síntese de oxalato à custa de ácido ascórbico.

A contaminação com $\mathrm{Zn}$ e Cd também estimulou a produção de tocoferol (Figura 4) nos diferentes tratamentos, quando comparados ao controle, com exceção do tratamento $\mathrm{Cd} 100 \mu \mathrm{mol} \mathrm{L}^{-1}$, devido provavelmente à sua grande toxicidade, o que causou grande estresse na planta e, consequentemente, uma diminuição significativa nos níveis de tocoferol. ${ }^{30}$ Resultados semelhantes foram encontrados em estudos com plantas de Lemna minor exposta a $\mathrm{Cd}$ e $\mathrm{Zn}$ por 9 dias, cujos níveis de $\alpha$-tocoferol aumentaram, gradualmente, até o $6^{\circ}$ dia de exposição aos metais. ${ }^{31}$

O tocoferol é capaz de eliminar peróxidos, formando radicais tocoferoxil. Os radicais tocoferoxil podem ser reciclados em tocoferol mediante ascorbato e GSH; desta forma, a redução nos níveis de tocoferol observada no tratamento $\mathrm{Cd} 100 \mu \mathrm{mol} \mathrm{L}{ }^{-1}$, possivelmente, deveu-se à rápida e grande redução de GSH nesse tratamento.

Danos no sistema fotossintético estão refletidos na redução dos níveis de clorofila e carotenoides, como de $\beta$-caroteno pela contaminação com Cd e Zn (Figura 5). 
(A)

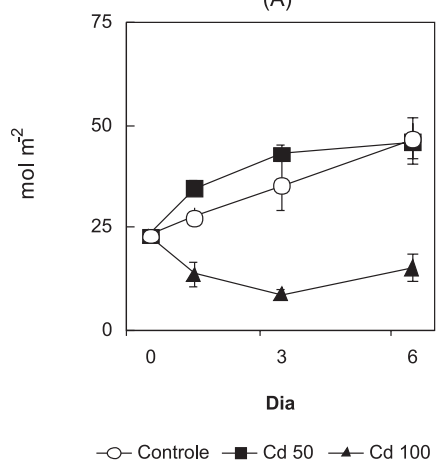

(B)

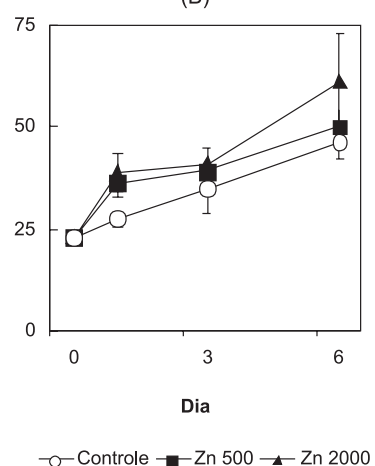

Figura 4. Produção de tocoferol em folhas de B. decumbens submetidas a diferentes doses com $\mathrm{Cd}(\mathrm{A})$ e $\mathrm{Zn}(B)$. As doses dos diferentes tratamentos de metais estão expressas em $\mu$ mol $L^{-1}$. Cada valor corresponde a uma média de 3 repetições \pm erro padrão
(A)

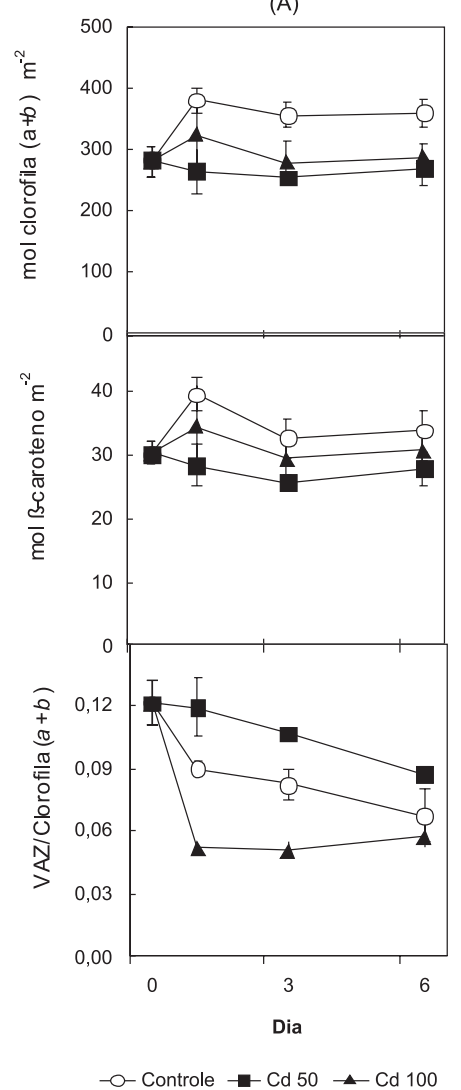

(B)

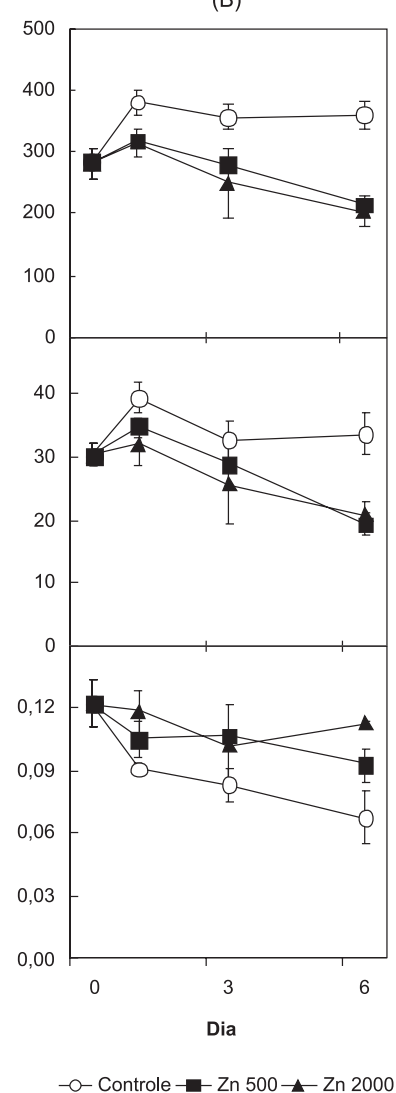

Figura 5. Teores de clorofila $(a+b)$, $\beta$-caroteno e VAZ/clorofila $(a+b)$ em folhas de B. decumbens submetidas a diferentes doses com Cd (A) e Zn (B). As doses dos diferentes tratamentos de metais estão expressas em $\mu$ mol $L^{-1}$. Cada valor corresponde a uma média de 3 repetições \pm erro padrão. VAZ: pigmentos do ciclo das xantofilas (violaxantina, anteraxantina e zeaxantina)

Os resultados indicam que o conteúdo de clorofila $a+b$ decresceu do controle para os tratamentos. A redução foi maior nos tratamentos contendo $\mathrm{Zn}$ quando comparados ao $\mathrm{Cd}$, principalmente no $6^{\circ}$ dia de exposição aos metais. Esses resultados confirmam que essa espécie foi mais sensível ao estresse causado pelo $\mathrm{Zn}$ do que pelo $\mathrm{Cd}$ nas doses estudadas.

O decréscimo do conteúdo de clorofila tem sido observado em várias espécies de plantas devido à contaminação com metais pesados, ${ }^{32,33}$ especialmente $\mathrm{Zn}$ que, frequentemente, inibe processos metabólicos através da inibição da ação de enzimas. O decréscimo no conteúdo de clorofila associado com o estresse de metais pesados pode ser resultado da inibição de enzimas responsáveis pela biossíntese de clorofila. ${ }^{34}$

A expressão de sintoma de clorose foi relacionada com o elevado conteúdo de metal nas folhas (Figura 1) e correspondeu a um decréscimo em ambas as concentrações de clorofila $a$ e $b$ (Figura 5), confirmando que o $\mathrm{Zn}$ e o $\mathrm{Cd}$ foram danosos ao aparato fotossintético da planta.

A concentração de $\beta$-caroteno, que apresentou um comportamento semelhante ao conteúdo de clorofila $a+b$, também foi menor em todos os tratamentos quando comparados ao controle, principalmente nas doses de $\mathrm{Zn}$ no $6^{\circ}$ dia de exposição ao metal, confirmando danos no sistema fotossintético das plantas após a contaminação. $O \beta$-caroteno é um eficiente agente de detoxicação de $\mathrm{O}_{2}$. Os carotenoides participam do sistema de antenas dos cloroplastos, na absorção de luz e transferência de energia para os centros das reações. Também podem dissipar energia durante o estresse fotoxidativo. ${ }^{35}$

A relação VAZ (pigmentos do ciclo da xantofila - violaxantina, anteraxantina e zeaxantina)/clorofila aumentou ligeiramente quando comparada ao controle (Figura 5), indicando uma resposta fotoprotetora do sistema fotossintético em resposta ao estresse provocado pela contaminação. ${ }^{31} \mathrm{O}$ tratamento com Cd $100 \mu \mathrm{mol} \mathrm{L}{ }^{-1}$ foi uma exceção, porque apresentou níveis muito baixos desses compostos fotoprotetores, devido provavelmente à toxicidade dessa dose aplicada.

\section{CONCLUSÕES}

A produção de fitoquelatinas e compostos antioxidantes (ascorbato e tocoferol) foi superior nos tratamentos com metais pesados quando comparados ao controle, mostrando uma resposta antioxidante dessas plantas quando submetidas à contaminação com metais pesados, sendo que o $\mathrm{Cd}$ foi o mais forte indutor de fitoquelatinas. A única exceção foi em relação à glutationa reduzida (GSH), já que seus níveis reduziram, provavelmente, devido à sua utilização para a síntese de fitoquelatinas.

Foram observados danos no sistema fotossintético das plantas após contaminação com $\mathrm{Cd}$ e Zn, principalmente pela redução nos níveis de clorofila e $\beta$-caroteno.

O estudo demonstrou que a $B$. decumbens foi uma espécie vegetal tolerante aos metais $\mathrm{Cd}$ e $\mathrm{Zn}$, acumulando concentrações moderadas dos mesmos em seus tecidos foliares (Figura 2S, material suplementar). No entanto, estudos adicionais são necessários visando melhor compreensão do mecanismo adaptativo da planta em resposta ao estresse provocado pelo excesso de $\mathrm{Cd}$ e $\mathrm{Zn}$.

\section{MATERIAL SUPLEMENTAR}

O material suplementar, disponível em http://quimicanova.sbq. org.br, em arquivo PDF e com acesso livre, traz figuras que mostram os teores de glutationa reduzida (GSH) e fitoquelatinas nas folhas das plantas de $B$. decumbens submetidas a diferentes tratamentos com $\mathrm{Cd}$ e $\mathrm{Zn}$ (Figura 1S) e os teores de ascorbato reduzido (AsA) e de-hidroascorbato (DHA) nas folhas das plantas de B. decumbens submetidas a diferentes doses de $\mathrm{Cd}$ e $\mathrm{Zn}$ (Figura 2S).

\section{AGRADECIMENTOS}

Ao apoio financeiro do $\mathrm{CNPq}$ e do projeto de pesquisa ETORTEK- BERRILUR-III-IE09-242 (Governo Basco, Espanha). Os autores gostariam de agradecer também ao Dr. J. I. García-Plazaola por seu envolvimento na metodologia de CLAE. 


\section{REFERÊNCIAS}

1. Santos, F. S.; Amaral Sobrinho, N. M. B.; Mazur, N. Em Nutrição Mineral de Plantas; Fernandes, M. S., ed.; SBCS: Viçosa, 2006, cap. 16.

2. Pongrac, P.; Zhao, F. J.; Razinger, J.; Zrimec, A.; Regvar, M.; Environ. Exp. Bot. 2009, 66, 479.

3. Clemens, S.; Planta 2001, 212, 475.

4. Wang, C.; Zhang, S. H.; Wang, P. F.; Hou, J.; Zhang, W. J.; Li, W.; Lin, Z. P.; Chemosphere 2009, 75, 1468.

5. Demming-Adams, B.; Adams, W. W.; Plant Physiol. 1993, 103, 1413.

6. Küpper, H.; Zhao, F.; McGrath, S. P.; Plant Physiol. 1999, 119, 305.

7. Wenzl, P.; Patiño, G. M.; Chaves, A. L.; Mayer, J. E.; Rao, I. M.; Plant Physiol. 2001, 125, 1473 .

8. Santos, F. S.; Hernández-Allica, J.; Becerril, J. M.; Amaral Sobrinho, N. M. B.; Mazur, N.; Garbisu, C.; Chemosphere 2006, 65, 43.

9. Hoagland, D. R.; Arnon, D. I.; Col. Agric. Exp. Stn. Circ. 1950, 347, 1.

10. Tedesco, M. J.; Gianello, C.; Bissani, C. A.; Bohnen, H.; Volkweiss, S. $\mathrm{J}$.; Análise de solo, plantas e outros materiais, $2^{\mathrm{a}}$ ed., UFRGS: Porto Alegre, 1995.

11. Hernández-Allica, J.; Garbisu, C.; Becerril, J. M.; Barrutia, O.; García-Plazaola, J. I.; Zhao, F. J.; McGrath, S. P.; Plant Cell Environ. 2006, 29, 1422.

12. García-Plazaola, J. I.; Artetxe, U.; Becerril, J. M.; Plant Sci. 1999, 143, 125.

13. García-Plazaola, J. I.; Becerril, J. M.; Phytochem. Anal. 1999, $10,1$.

14. García-Plazaola, J. I.; Becerril, J. M.; Australian J. Plant Physiol. 2001, $28,225$.

15. Orroño, D. I.; Lavado, R. S.; Revista Internacional de Botánica Experimental 2009, 78, 75.
16. Dixit, V.; Pandey, V.; Shyam, R.; J. Exp. Bot. 2001, 52, 1101.

17. Piqueras, A.; Olmos, E.; Martínez-Solano, J. R.; Hellín, E.; Free Radical Res. 1999, 31, 33.

18. Kubota, H.; Sato, K.; Yamada, T.; Maitani, T.; Plant Sci. 1995, 106, 157. 19. Pawlik-Skowronska, B.; Aquat. Toxicol. 2003, 62, 155.

20. Tsuji, N.; Hirayanagi, N.; Iwabe, O.; Namba, T.; Tagawa, M.; Miyamoto, S.; Miyasaka, H.; Takagi, M.; Hirata, K.; Miyamoto, K.; Phytochemistry 2003, 62, 453.

21. Zenk, M. H.; Gene 1996, 179, 21.

22. Cobbett, C.; Goldsbrough, P.; Annu. Rev. Plant Biol. 2002, 53, 159.

23. Klapheck, S.; Fliegner, W.; Zimmer, I.; Plant Physiol. 1994, 104, 1325.

24. Loewus, F. A. Em The Biochemistry of Plants; Preiss, J., ed.; Academic Press: New York, 1988, cap. 3.

25. Sandalio, L. M.; Dalurzo, H. C.; Gómez, M.; Romero-Puertas, M. C.; del Río, L. A.; J. Exp. Bot. 2001, 52, 2115.

26. González, A.; Steffen, K. L.; Lynch, J.; Plant Physiol. 1998, 118, 493.

27. Demirevska-Kepova, K.; Simova-Stoilova, L.; Stoyanova, Z.; Hölzer, R.; Feller, U.; Environ. Exp. Bot. 2004, 52, 253.

28. Smirnoff, N.; Curr. Opin. Plant Biol. 2000, 3, 229.

29. González, A.; Lynch, J.; Aust. J. Plant Physiol. 1999, 26, 811.

30. Munné-Bosch, S.; Alegre, L.; Crit. Rev. Plant Sci. 2002, 21, 3.

31. Artetxe, U.; García-Plazaola, J. I.; Hernández, A.; Becerril, J. M.; Plant Physiol. Biochem. 2002, 40, 859.

32. Oncel, I.; Keles, Y.; Ustun, A. S.; Environ. Pollut. 2000, 107, 315.

33. Mobin, M.; Khan, N. A.; J. Plant Physiol. 2007, 164, 601.

34. Stobart, A. K.; Griffiths, W. T.; Ameen-Bukhari, I.; Sherwood, R. P.; Plant Physiol. 1985, 63, 293.

35. Baker, C. J.; Orlandi, E. W.; Annu. Rev. Phytopathol. 1995, 33, 299. 


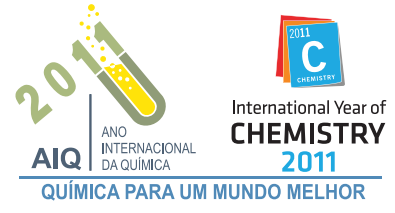

RESPOSTA ANTIOXIDANTE, FORMAÇÃO DE FITOQUELATINAS E COMPOSIÇÃO DE PIGMENTOS FOTOPROTETORES EM Brachiaria decumbens Stapf SUBMETIDA À CONTAMINAÇÃO COM Cd E Zn

Fabiana Soares dos Santos

Departamento de Engenharia de Agronegócios, Universidade Federal Fluminense, Av. dos Trabalhadores, 420, 27255-125

Volta Redonda - RJ, Brasil

Nelson Moura Brasil do Amaral Sobrinho e Nelson Mazur*

Departamento de Solos, Instituto de Agronomia, Universidade Federal Rural do Rio de Janeiro, BR 465, km 7, 23890-000 Seropédica - RJ, Brasil

\section{Carlos Garbisu}

Departamento de Ecosistemas, Instituto Vasco de Investigación y Desarrollo Agrario, Berreaga 1, E-48160 Derio, Bizkaia, Espanha Oihana Barrutia y José Maria Becerril

Departamento de Biología Vegetal Y Ecología, Universidad del País Vasco, PO Box 644, E-48080 Bilbao, Espanha

(A)

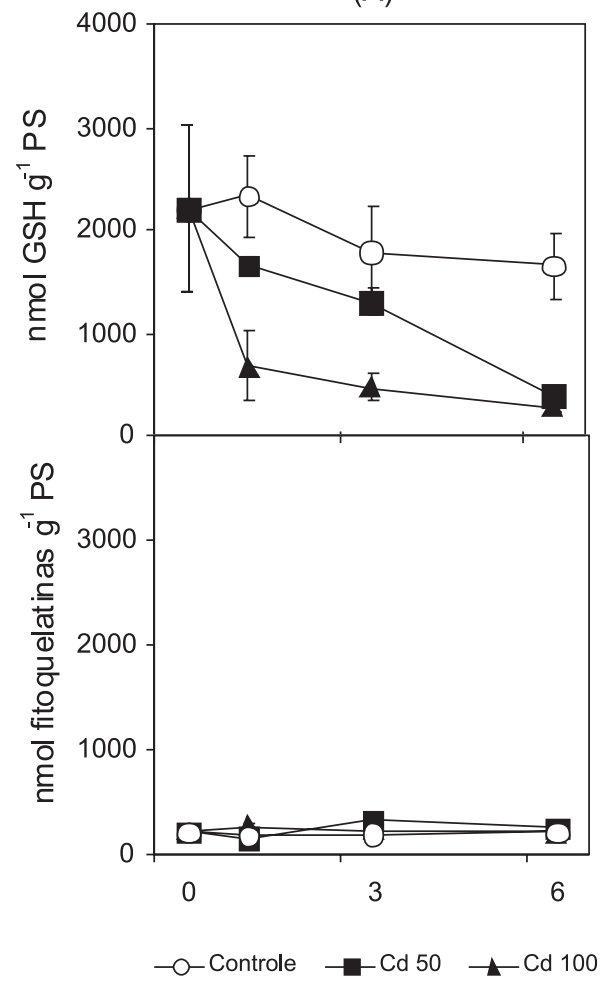

(B)

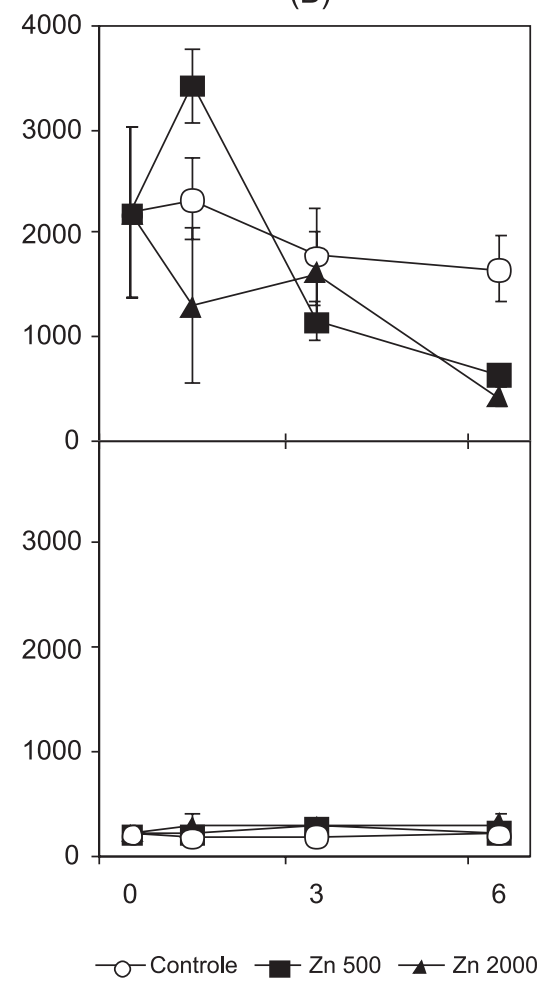

Figura 1S. Teores de glutationa reduzida (GSH) e fitoquelatinas nas folhas das plantas de B. decumbens submetidas a diferentes tratamentos com Cd (A) e Zn (B). As doses dos diferentes tratamentos de metais estão expressas em $\mu$ mol $L^{-1}$. Cada valor corresponde a uma média de 3 repetições \pm erro padrão

*e-mail: nelmazur@ufrrj.br 
(A)

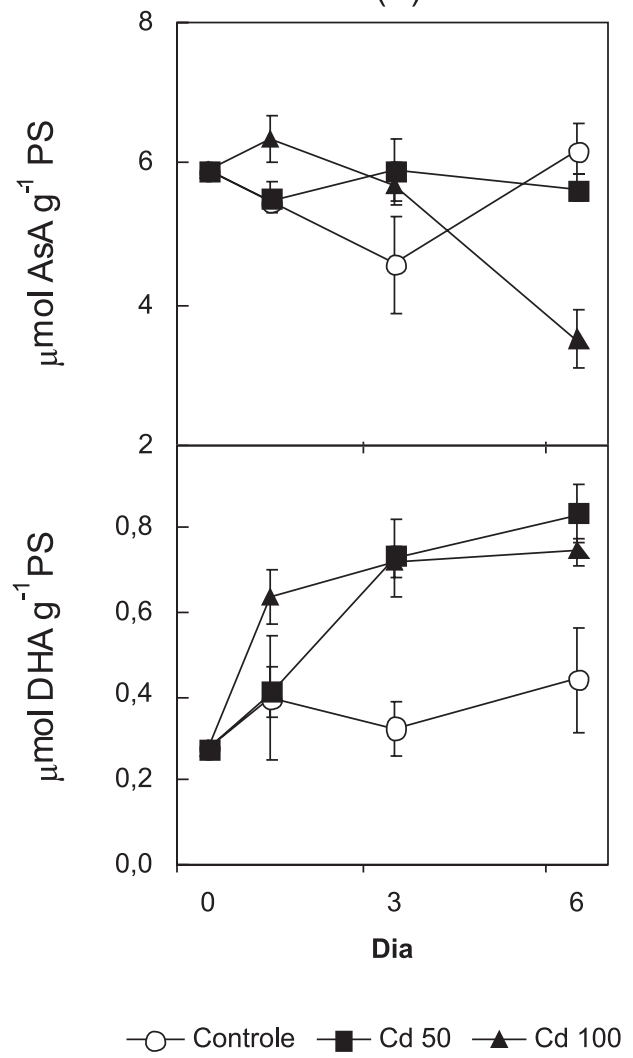

(B)

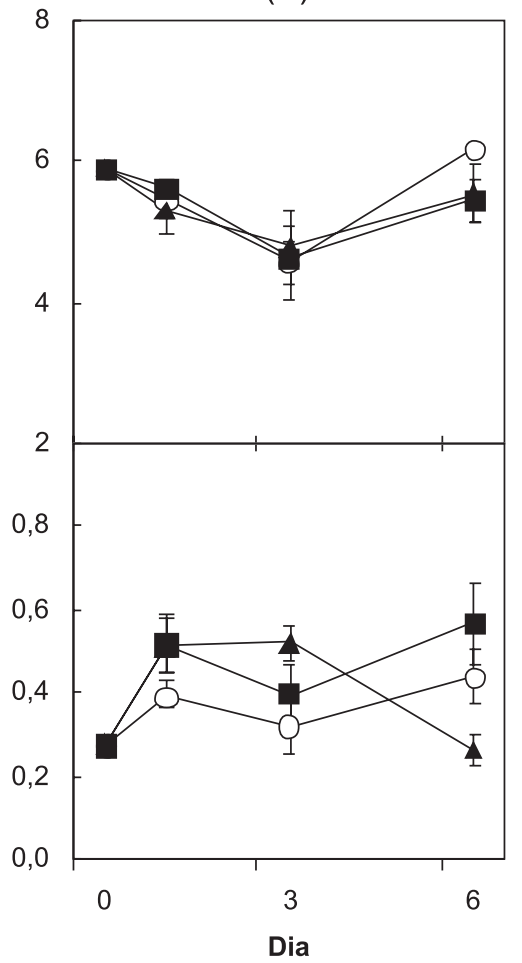

- - Controle $\rightarrow-\mathrm{Zn} 500 \rightarrow$ Zn 2000

Figura 2S. Teores de ascorbato reduzido (AsA) e de-hidroascorbato (DHA) nas folhas das plantas de B. decumbens submetidas a diferentes doses de Cd (A) e Zn (B). As doses dos diferentes tratamentos de metais estão expressas em $\mu$ mol $\mathrm{L}^{-1}$. Cada valor corresponde a uma média de 3 repetições \pm erro padrão 